Applied nutritional investigation

\title{
The association of excessive growth with development of general and central obesity at 7 years of age in every period after birth in Chilean children
}

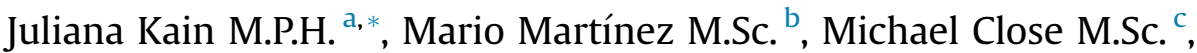 \\ Ricardo Uauy Ph.D. ${ }^{a}$, Camila Corvalán Ph.D. ${ }^{a}$ \\ a Institute of Nutrition and Food Technology, University of Chile, Santiago, Región Metropolitana, Chile \\ ${ }^{\mathrm{b}}$ Statistics, University of Manchester, Manchester, United Kingdom \\ ${ }^{\mathrm{c}}$ Gillings School of Global Public Health, University of North Carolina at Chapel Hill, Chapel Hill, North Carolina, USA
}

\section{A R T I C L E I N F O}

\section{Article history:}

Received 17 July 2015

Accepted 26 September 2015

\section{Keywords:}

Childhood obesity

Incidence

Prevalence

Tracking

Chile

\begin{abstract}
A B S T R A C T
Objective: To determine whether overweight or obesity between 0 and $6 \mathrm{y}$ increases the probability of developing general/central obesity at $7 \mathrm{y}$.

Methods: Weight, height, and waist circumference were assessed between 0 and $6 \mathrm{y}$ in 628 Chilean children. Body mass index, incidence of overweight (IOW), incidence of obesity (IOB), and prevalence at birth and 0 to 6, 6 to 24, 24 to 48 , and 48 to 72 mo and odds ratio (OR) and 95\% confidence interval $(95 \% \mathrm{CI})$ for developing obesity/central obesity at 84 mo were calculated by sex.

Results: IOW was highest at 6 to $24 \mathrm{mo}$ (20.3\% and 21.1\% for girls and boys, respectively); IOB was highest at 6 to 24 and 24 to $48 \mathrm{mo}$ ( $11 \%$ and $10 \%$, respectively). OR for developing obesity at 7 y was significant if overweight was present 24 to $48 \mathrm{mo}$ in girls and 6 to $24 \mathrm{mo}$ in boys OR 2.47 [95\% CI, 1.5-4] and OR 2.26 [95\% Cl, 1.30-3.92], respectively, and much higher for children who were obese, OR 6.1 (95\% CI, 3.03-12.21) for girls 6 to 24 mo and OR 6.57 (95\% CI, 2.55-16.86) for boys 0 to 6 mo. IOW or IOB was not associated with obesity at $84 \mathrm{mo}$, except for the previous period. Overweight also increased the risk of central obesity very early on, after 6 mo in girls and after birth in boys OR 3.8 [95\% CI, 2.3-6.2] and OR 2.5 [95\% CI, 2.04-3] at 6 to 24 and 0 to 6 mo, respectively, whereas obesity in all periods was associated with a significantly higher OR of presenting central obesity at $7 \mathrm{y}$. Conclusion: There is tracking not only of obesity but also of overweight after birth for developing general or central obesity at $7 \mathrm{y}$. Prevention should begin very early on.
\end{abstract}

(c) 2016 Elsevier Inc. All rights reserved.

\section{Introduction}

Although childhood obesity has risen markedly over the last decades in practically every country, its increase has been significantly greater in middle- and low-income countries, especially in those where the epidemiologic and nutritional transition has occurred in a short period [1]. In Chile, a middleincome country, childhood obesity has tripled over the last decades and continues to rise. Presently, 25\% of 6 y old children are obese and $30 \%$ are overweight [2], making it one of the countries with the highest childhood obesity rates in the world [3].

Children who gain weight rapidly, independent of birth weight, are more likely to be obese in midchildhood and later in

\footnotetext{
* Corresponding author. Tel.: +56 229781453; fax: +56 222214030.

E-mail address: jkain@inta.uchile.cl (J. Kain).
}

life [4-6]. Many studies have attempted to determine critical periods in infancy associated with obesity in midchildhood, adolescence, and adulthood. One of the earlier reviews [4] reported that three critical periods, namely, pregnancy, obesity rebound, and puberty, are associated with adult obesity. Later studies have examined the relationship between excessive growth during specific periods with either childhood and adolescent obesity. If excessive weight gain occurs as early as the first weeks of life [7] and if it occurs from birth to 4 mo [8], there is an increased risk of later obesity. In Project Viva, an ongoing prospective cohort study [9] of pregnant women and their children, the authors found that rapid increases in weight for length in the first 6 mo of life were associated with sharply increased risk of obesity at $3 \mathrm{y}$ of age. Similarly, in the Early Bird longitudinal study of British children [10], the authors observed that overweight gained by $5 \mathrm{y}$ of age was a greater risk factor than 
that gained after that age, in determining overweight or obesity at $11 \mathrm{y}$. In contrast, a study based on Avon Longitudinal Study of Parents and Children, a large prospective study of English children followed from birth to $15 \mathrm{y}$ [11], reported that most overweight occurred between 5 and $9 \mathrm{y}$, whereas gains before $5 \mathrm{y}$ were gradual.

In 2006, we enrolled 1190 three-year-old children with no medical condition that could hamper the study (checked from their health records) from preschools serving low-income and middle-low-income households into a prospective cohort study, the Growth and Obesity Chilean Cohort Study (GOCS cohort). Presently, the children are $11 \mathrm{y}$ of age. When the children were $5 \mathrm{y}$ of age, we reported that $18.6 \%$ and $12.6 \%$ of boys and girls were obese, and $25.8 \%$ and $25.5 \%$ were overweight, respectively [12]. Among those obese at $5 \mathrm{y}$, we observed rapid weight gain occurring very early in life (from around $6 \mathrm{mo}$ ). We also found that there was an association between body mass index (BMI) $Z$ score and height, especially after $3 \mathrm{y}$, and that the probability of a preschool child becoming obese was less than $10 \%$ if his/her height $Z$ score was below the median of the reference $(Z$ score $<0)$. In contrast, children with heights above the median (even within normal range) had an increased risk of obesity [13]. We also found in this cohort that, at $4 \mathrm{y}$ of age, children had at least one cardiometabolic risk factor, particularly related to lipid disorders [14], and that $44 \%$ of the children had an early adiposity rebound $(<5 \mathrm{y})$ that was associated with metabolic risk at $7 \mathrm{y}$ of age [15].

The present study examined whether there are early life periods in which having overweight or obesity increases the odds of developing obesity in midchildhood. Therefore, we aimed to evaluate sex-specific incidence and prevalence of overweight and obesity for each period between birth and $6 \mathrm{y}$, and to assess how each of these relates to obesity and central obesity at $7 \mathrm{y}$.

\section{Materials and methods}

Study cohort and procedures

The GOCS cohort has been described in detail elsewhere [15]. Briefly, 1190 children with anthropometric data from birth were enrolled at $3 \mathrm{y}$ of age in 2006. Weight and height measurements from birth until 36 mo of age were obtained retrospectively from the child's health record provided by the mother/guardian. These measurements were taken at well-baby clinics by trained nurses or nutritionists. Infant's weight up to 24 mo was obtained using a pediatric balance beam scale with a precision of $10 \mathrm{~g}$, recumbent length was obtained with $0.1 \mathrm{~cm}$ accuracy. After $24 \mathrm{mo}$, weight was measured with a balance beam scale with a precision of $100 \mathrm{~g}$ and height with a stadiometer, accurate to $0.1 \mathrm{~cm}$. In 2007 , we administered a questionnaire to 1020 mothers to collect data on a range of socioeconomic, prenatal, and postnatal characteristics. Since 2007 we have been measuring annually the children's weight, height, and waist circumference (WC). We measured weight to the nearest $0.1 \mathrm{~kg}$, height to the nearest $0.1 \mathrm{~cm}$, and WC to the nearest $0.1 \mathrm{~mm}$. We calculated BMI and defined children with overweight as those having a BMI $Z$ score between +1 and +2 and obesity with a BMI $Z$ score $>+2$, according to World Health Organization (WHO) [16,17].

We measured the weight status evolution of children using BMI rather than weight for two reasons. First, the WHO recommends classification of child nutritional status by BMI $Z$ score and, second, the correlation between weight and BMI $Z$ score is high at these ages [10].

The most commonly used WC cutoff to define central obesity is the 90th percentile $[18,19]$; however, in our population, this cutoff resulted in a nearly identical categorization as general obesity defined by BMI $Z$ score. Instead, we used WC with the 75th percentile cutoff of NHANES III, which gave a lower concordance between them.

To identify early life periods of interest, we considered age brackets often cited in the literature as potential critical periods for later overweight $[4,5,20]$. These age brackets also coincide with the ages in which the children were measured: at birth and 0 to 6,6 to 24,24 to 48,48 to 72 , and greater than 72 mo (mean age, $84 \mathrm{mo}$ ).

The sample for this study was restricted to children with at least one anthropometric measurement in every period studied between birth and $7 \mathrm{y}$ $(\mathrm{n}=628)$. The number of children not included was 562 , mainly because during the first $3 \mathrm{y}$, their visits to the well-baby clinics were sporadic. As reported in the Results section, there were no meaningful differences between characteristics of children who were included versus those excluded. For each period, we determined the incidence and prevalence rates of overweight and obesity.

The Ethics Committee for Human Studies of the Institute of Nutrition and Food Technology, University of Chile, approved this study. In addition, a signed informed consent form was obtained from a parent/guardian of every child.

Statistical analyses

To assess if certain characteristics of children not included were different from those of study participants, we compared the distribution of the following variables in both groups of children: sex, birth weight, percentage of mothers who were obese before pregnancy, BMI $Z$ score, \% overweight and obesity at $7 \mathrm{y}$, mother's schooling, and presence of fathers at home, using $t$ tests and chi-squared tests.

To determine incidence and prevalence during each study period, if more than one measurement was recorded for the child during that same period, we considered the one closer to the higher age of the study period. This was done to avoid the possibility of considering a child as prevalent and non-prevalent during the same period. Thus, each subject contributed only one single measurement per period. We report the mean age and SD that children had during each period that was calculated from the dates that single measurement was taken.

In each period we determined mean weight, height, WC, BMI $Z$ score, and proportion of children with WC $>75$ th percentile by sex. In addition, we determined the incidence (new cases over total potential new cases) and prevalence (total number of cases over total study participants) of overweight and obesity by sex. Two outcomes of interest were defined: developing general obesity at 84 mo ( 1 if the child was obese at $84 \mathrm{mo}, 0$ if normal weight) and central obesity at $84 \mathrm{mo}$ ( 1 if central obesity was present at $84 \mathrm{mo}, 0$ otherwise). We determined the odds ratio (OR) and 95\% confidence interval (95\% CI) for developing general obesity and central obesity at 84 mo, according to the incidence ( 1 if the child was incident in that period, 0 otherwise) and prevalence ( 1 if the child was prevalent, 0 otherwise) of overweight and obesity in every previous period. These analyses were done with contingency tables (three entries): one for obesity at 84 mo (yes/no), one for sex (female/male), and the third one for nutritional status at the specific period (overweight, yes/no; obesity, yes/no). In the event of absence of cases during the study period, ORs were not calculated, because they had a zero denominator. Statistical analyses were performed with R Software.

\section{Results}

No significant differences were observed between study participants included in and those excluded from the analyses, although included children had a higher BMI $Z$ score at $7 \mathrm{y}$ ( 1.01 and 0.92 versus 0.93 and 0.84 , boys and girls, respectively) and had a higher proportion of obese mothers before pregnancy ( $8.9 \%$ versus $5.3 \%$ in boys, and $6.5 \%$ versus $6.1 \%$ in girls) (results not shown).

Table 1 shows the anthropometric characteristics of participants in each time period from 0 to 84 mo according to sex. At birth, girls had a higher BMI $Z$ score than boys did, increasing progressively until about 23 mo and remaining relatively stable thereafter. Among boys, BMI $Z$ score followed a similar trend, but was higher than those of girls after $48 \mathrm{mo}$. The prevalence of children with excess weight (BMI $Z$ score $>1$ ) increased with age, reaching almost half the children at 84 mo, whereas about onethird of boys and girls had high WC (measured from $48 \mathrm{mo}$ onward) at $84 \mathrm{mo}$.

Table 2 shows the incidence and prevalence of overweight and obesity in each time period by sex. Among girls, the incidence of overweight (IOW) was around $17 \%$ until 6 mo, reached $20 \%$ between 6 and $24 \mathrm{mo}$, and decreased thereafter to slightly over $5 \%$ at $>72 \mathrm{mo}$. Among boys, a similar pattern was observed, though the IOW at birth was lower than that among girls $(11.5 \%$ versus $16.4 \%$ ). The incidence of obesity (IOB) in girls was around $5 \%$ in all periods, except between 6 and 24 mo, when it was $11.0 \%$. Among boys, the IOB was highest between 24 and 48 mo (10.0\%), whereas incidence in the remaining periods was around $6 \%$. Obesity prevalence increased with age in both sexes, reaching 
Table 1

Anthropometric characteristics of the sample by time periods and sex $(n=628)$

\begin{tabular}{|c|c|c|c|c|c|c|}
\hline & \multicolumn{6}{|c|}{ Periods (months) } \\
\hline & 0 & $0-6$ & $6-24$ & $24-48$ & $48-72$ & $>72$ \\
\hline \multicolumn{7}{|l|}{ Girls $(n=323)$} \\
\hline Mean age (mo) (SD) & $0(0)$ & $5.3(0.6)$ & $23(1.2)$ & $38.1(3.5)$ & $62.1(4.1)$ & $84(5.2)$ \\
\hline Weight (kg) & $3.4 \pm 0.4$ & $7.27 \pm 1.1$ & $12.2 \pm 1.5$ & $15.4 \pm 2.2$ & $20.6 \pm 3.9$ & $26.3 \pm 5.2$ \\
\hline Height $(\mathrm{cm})$ & $49.7 \pm 1.7$ & $64.2 \pm 3.5$ & $84.9 \pm 4.0$ & $95.8 \pm 4.3$ & $110.2 \pm 5.8$ & $122.2 \pm 5.5$ \\
\hline BMI & $13.8 \pm 1.3$ & $17.6 \pm 1.7$ & $17.0 \pm 1.6$ & $16.8 \pm 1.6$ & $16.88 \pm 2.0$ & $17.5 \pm 2.6$ \\
\hline $\mathrm{WC}(\mathrm{cm})$ & nd & nd & nd & nd & $55.10 \pm 5.17$ & $59.84 \pm 6.98$ \\
\hline BMI $Z$ & $0.3 \pm 1.0$ & $0.5 \pm 1.0$ & $0.9 \pm 1.0$ & $0.9 \pm 1.0$ & $0.9 \pm 1.0$ & $0.9 \pm 1.1$ \\
\hline BMI $Z>1(\%)$ & 21.7 & 29.1 & 46.4 & 45.2 & 40.6 & 46.1 \\
\hline WC $>P 75$ (NHANES) & nd & nd & nd & nd & 22.3 & 34.8 \\
\hline \multicolumn{7}{|l|}{ Boys $(n=305)$} \\
\hline Mean age (mo) (SD) & $0(0)$ & $5.1(0.4)$ & $23.1(1.5)$ & $38.9(3.3)$ & $62.5(4)$ & $84.5(4.8)$ \\
\hline Weight (kg) & $3.5 \pm 0.4$ & $7.6 \pm 1.3$ & $12.7 \pm 1.6$ & $15.7 \pm 2.1$ & $20.9 \pm 3.5$ & $26.5 \pm 5.3$ \\
\hline Height $(\mathrm{cm})$ & $50.2 \pm 1.8$ & $65.0 \pm 4.3$ & $85.9 \pm 4.1$ & $97.1 \pm 4.5$ & $1110.0 \pm 5.4$ & $122.9 \pm 5.1$ \\
\hline BMI & $13.7 \pm 1.6$ & $17.9 \pm 1.8$ & $17.2 \pm 1.5$ & $16.7 \pm 1.5$ & $16.9 \pm 2.0$ & $17.4 \pm 2.6$ \\
\hline $\mathrm{WC}(\mathrm{cm})$ & nd & nd & nd & nd & $54.98 \pm 4.8$ & $59.6 \pm 7.11$ \\
\hline BMI Z & $0.1 \pm 1.2$ & $0.5 \pm 1.1$ & $0.9 \pm 1.0$ & $0.8 \pm 1.1$ & $1.0 \pm 1.2$ & $1.0 \pm 1.3$ \\
\hline BMI Z > $1(\%)$ & 17.4 & 31.8 & 44.3 & 41 & 45.6 & 43.6 \\
\hline WC $>P 75$ (NHANES) & nd & nd & nd & nd & 21.9 & 36.6 \\
\hline
\end{tabular}

BMI, body mass index; nd, not determined; NHANES, National Health and Nutrition Examination Survey; WC, waist circumference.

$17 \%$ among girls and $21.3 \%$ among boys at $84 \mathrm{mo}$; in contrast, overweight prevalence was more or less stable across periods.

Table 3 shows the OR and 95\% CI for developing obesity at 84 mo, according to the incidence and prevalence of overweight or obesity in each time period, by sex. Being overweight in infancy ( 0 to 6 mo among girls and 6 to 24 mo among boys) almost doubled the risk of obesity at 84 mo OR 1.86 [95\% CI, 1.093.2] and OR 2.26 [95\% CI, 1.30-3.92], respectively; as expected, the probability of being obese at $7 \mathrm{y}$ is even higher for children who were obese during infancy: OR 6.6 (95\% CI, 2.55-16.86) for boys 0 to $6 \mathrm{mo}$, and OR 6.1 (95\% CI, 3.03-12.21) for girls 6 to 24 mo.

Being a new case of overweight (incident) in any period was not associated with obesity at $84 \mathrm{mo}$, except after $48 \mathrm{mo}$; however, being prevalent was positively associated after 6 mo in boys and $24 \mathrm{mo}$ in girls.

Table 2

Incidence and prevalence of overweight and obesity by time periods from birth to $7 \mathrm{y}(\%)$

\begin{tabular}{|c|c|c|c|c|c|c|}
\hline & \multicolumn{6}{|c|}{ Periods (months) } \\
\hline & 0 & $0-6$ & $6-24$ & $24-48$ & $48-72$ & $>72$ \\
\hline \multicolumn{7}{|l|}{ Girls $(n=323)$} \\
\hline $\begin{array}{l}\text { Age (mo), } \\
\text { mean }(\mathrm{SD})\end{array}$ & $0(0)$ & $5.3(0.6)$ & $23(1.2)$ & $38.1(3.5)$ & $62.1(4.1)$ & $84(5.2)$ \\
\hline \multicolumn{7}{|l|}{ Overweight } \\
\hline Incidence & 16.4 & 18.0 & 20.3 & 14.3 & 6.1 & 5.2 \\
\hline Prevalence $^{\dagger}$ & 16.4 & 23.5 & 33.1 & 34.1 & 28.2 & 29.1 \\
\hline \multicolumn{7}{|l|}{ Obesity } \\
\hline Incidence & 5.3 & 5.2 & 11.0 & 5.0 & 5.3 & 5.2 \\
\hline Prevalence $^{\dagger}$ & 5.3 & 5.6 & 13.3 & 11.2 & 12.4 & 17.0 \\
\hline \multicolumn{7}{|l|}{ Boys $(\mathrm{n}=305)$} \\
\hline $\begin{array}{l}\text { Age (mo), } \\
\text { mean }(\mathrm{SD})\end{array}$ & $0(0)$ & $5.1(0.4)$ & $23.1(1.5)$ & $38.9(3.3)$ & $62.5(4)$ & $84.5(4.8)$ \\
\hline \multicolumn{7}{|l|}{ Overweight } \\
\hline Incidence & 11.5 & 20.9 & 21.1 & 9.6 & 10.3 & 4.9 \\
\hline Prevalence & 11.5 & 25.3 & 32.5 & 24.6 & 27.2 & 22.3 \\
\hline \multicolumn{7}{|l|}{ Obesity } \\
\hline Incidence & 5.9 & 5.9 & 7.8 & 10.0 & 8.5 & 5.4 \\
\hline Prevalence $^{\dagger}$ & 5.9 & 6.6 & 11.8 & 16.4 & 18.4 & 21.3 \\
\hline
\end{tabular}

BMI, body mass index.

* Defined as $1<$ BMI $Z \leq 2$.

Defined as BMI $Z>2$.
Table 4 shows the OR and 95\% CI for developing central obesity at $84 \mathrm{mo}$, according to the incidence and prevalence of overweight or obesity in each period. Here we observe that being overweight increases the risk of central obesity after 6 mo of life in girls and after birth in boys OR 3.77 [95\% CI, 2.3-6.18] and OR 2.5 [95\% CI, 2.04-3.05], respectively. Conversely, being obese in all periods (except at birth in boys) was associated with an increased risk of presenting central obesity at $7 \mathrm{y}$ : OR $5.6(95 \% \mathrm{CI}$, 3.63-8.49) and OR $6.2(95 \% \mathrm{CI}, 4.46-8.54)$ for boys 0 to 6 and 6 to 24 mo, respectively, and OR 4.3 (95\% CI, 3.26-5.65) and OR 18 (95\% CI, 11.74-26.18) for girls 6 to 24 and 24 to $48 \mathrm{mo}$, respectively.

IOW was not associated with central obesity in any of the periods, except after $4 \mathrm{y}$; we were unable to estimate the effect of the IOB, because the sample size was too small to assess this association with adequate precision.

\section{Discussion}

Our study shows that the largest proportion of new cases of obesity and overweight develop from birth to $2 \mathrm{y}$, especially between 6 and $24 \mathrm{mo}$, among $7 \mathrm{y}$ old low-income and middlelow-income children born with birth weight $\geq 2500 \mathrm{~g}$ in Chile. We also observe that being obese at any period after birth increases the risk of both obesity and central obesity at $7 \mathrm{y}$. More importantly, being overweight early in life is also associated with an increased risk of obesity and central obesity at $7 \mathrm{y}$. Overall, these results suggest that infancy may be a critical period for obesity and central obesity development.

There is disagreement in the literature regarding the effects of excessive growth at early ages on later obesity. The inconsistent findings may relate to differences in sample characteristics, definition of time spans, and methodological techniques employed. Baird et al. [5] reviewed 24 studies to assess the association between growth in infancy and later obesity. These studies found that, among infants with rapid growth, the OR of later obesity ranged from 1.17 to 5.7. However, the relationship may vary by duration of breast-feeding and age of introduction of complementary foods, as these factors relate to whether lean or fat mass drives weight gain [21]. Rapid weight gain mostly because of linear growth produces a greater increase in lean 
Table 3

Odds ratio for developing obesity at $7 \mathrm{y}$ according to incidence and prevalence of overweight and obesity in different periods from birth to $7 \mathrm{y}$ (months)

\begin{tabular}{|c|c|c|c|c|c|}
\hline & \multicolumn{5}{|l|}{ Periods (months) } \\
\hline & \multirow[b]{2}{*}{ OR (95\% CI) } & \multirow{2}{*}{$\frac{0-6}{\mathrm{OR}(95 \% \mathrm{CI})}$} & \multirow{2}{*}{$\frac{6-24}{\text { OR }(95 \% \mathrm{CI})}$} & \multirow{2}{*}{$\frac{24-48}{\text { OR }(95 \% \mathrm{CI})}$} & $48-72$ \\
\hline & & & & & OR (95\% CI) \\
\hline \multicolumn{6}{|l|}{ Girls $(n=323)$} \\
\hline Age (mo) (mean) & 0 & 5.3 & 23 & 38.1 & 62.1 \\
\hline \multicolumn{6}{|l|}{ Overweight } \\
\hline Incidence ${ }^{*}$ & $0.89(0.48-1.67)$ & $0.65(0.35-1.20)$ & $0.93(0.51-1.70)$ & $0.73(0.36-1.47)$ & $4.56(1.00-20.70)$ \\
\hline Prevalence ${ }^{\dagger}$ & $1.45(0.78-2.70)$ & $1.86(1.09-3.2)$ & $1.57(0.96-2.59)$ & $2.47(1.50-4.06)$ & $8.83(5.09-15.34)$ \\
\hline \multicolumn{6}{|l|}{ Obesity } \\
\hline Incidence $^{*}$ & $0.21(0.06-0.70)$ & $0.24(0.07-0.79)$ & $0.57(0.25-1.32)$ & $3.33(0.86-12.92)$ & $5.75(1.21-27.4)$ \\
\hline Prevalence ${ }^{\dagger}$ & $1.54(0.48-4.91)$ & $1.42(0.45-4.5)$ & $6.09(3.03-12.21)$ & $19.5(8.72-43.5)$ & $91.74(32.5-263.2)$ \\
\hline \multicolumn{6}{|l|}{ Boys $(n=305)$} \\
\hline Age (mo) (mean) & 0 & 5.1 & 23.1 & 38.9 & 62.5 \\
\hline \multicolumn{6}{|l|}{ Overweight } \\
\hline Incidence ${ }^{*}$ & $0.78(0.38-1.62)$ & $0.76(0.42-1.39)$ & $0.73(0.40-1.35)$ & $1.33(0.55-3.19)$ & $1.51(0.61-3.74)$ \\
\hline Prevalence $^{\dagger}$ & $0.85(0.36-2.06)$ & $1.44(0.80-2.62)$ & $2.26(1.30-3.92)$ & $2.59(1.45-4.63)$ & $5.41(3.03-9.63)$ \\
\hline \multicolumn{6}{|l|}{ Obesity } \\
\hline Incidence ${ }^{*}$ & $0.1(0.03-0.37)$ & $1.36(0.46-3.98)$ & $0.58(0.22-1.50)$ & $0.71(0.29-1.73)$ & $7.8(1.70-35.71)$ \\
\hline Prevalence ${ }^{\dagger}$ & $0.73(0.20-2.59)$ & $6.57(2.55-16.86)$ & $5.42(2.62-11.21)$ & $12(6.04-23.70)$ & $67.11(28.41-158.73)$ \\
\hline
\end{tabular}

OR (95\% CI), odds ratio (95\% confidence interval).

* Defined as $1<$ BMI $Z \leq 2$.

Defined as BMI $Z>2$.

mass than fat mass, whereas rapid fat mass accrual during infancy is a better predictor of childhood obesity [22].

Our study also shows that the presence of obesity at any time during childhood is associated with higher risk of obesity at $7 \mathrm{y}$, suggesting moderate tracking of this condition. Other studies have also reported similar results in follow-ups from birth until school age or adolescence. In the Norwegian Mother and Child Cohort Study [23], in which 3771 children born between 2002 and 2004 were followed until $7 \mathrm{y}$ of age, a fair to moderate tracking of body size was observed in that period. In Japan, a retrospective study tracking anthropometric measures of obese $5 \mathrm{y}$ olds reported that these children had significantly higher BMI percentiles from birth compared with those of normal-weight $5 \mathrm{y}$ olds [24]. In Iceland, tracking of overweight and obesity in cohorts born in 1988 and 1994 followed through puberty found that $51 \%$ of overweight 6 y olds were still overweight at puberty.
However, children who were overweight at $2.5 \mathrm{y}$ (but not later) did not have an increased risk of overweight at puberty [25].

This study shows a sex difference in incidence and prevalence of overweight and obesity as well as the probability of developing general and central obesity, especially after 24 mo of age, with boys presenting higher prevalence rates after 24 mo. Previous analyses with children from this cohort have reported that boys have higher obesity prevalence than girls [15,26], and results from a cross-sectional study that included a national sample of children of 4 to $6 y$ of age show exactly the same [27].

Several studies done elsewhere and also in this cohort have found that prenatal and postnatal risk factors are associated with obesity in early and midchildhood [26,28-31]. These include prepregnancy weight, gestational weight gain, high birth weight, rapid weight/height gain during infancy, birth order, and sleep duration. Recently, a study [32] reported that at both 4 and $6 \mathrm{y}$

Table 4

Odds ratio for developing central obesity at $7 \mathrm{y}$ according to incidence and prevalence of overweight and obesity in different periods from birth to $7 \mathrm{y}$ (months)

\begin{tabular}{|c|c|c|c|c|c|}
\hline & \multicolumn{5}{|l|}{ Periods (months) } \\
\hline & \multirow[b]{2}{*}{ OR (95\% CI) } & \multirow{2}{*}{$\frac{0-6}{\text { OR }(95 \% \mathrm{CI})}$} & \multirow{2}{*}{$\frac{6-24}{\text { OR }(95 \% \mathrm{CI})}$} & $24-48$ & $48-72$ \\
\hline & & & & OR (95\% CI) & OR $(95 \% \mathrm{CI})$ \\
\hline \multicolumn{6}{|l|}{ Girls $(n=323)$} \\
\hline Age (mo) (mean) & 0 & 5.3 & 23 & 38.1 & 62.1 \\
\hline \multicolumn{6}{|l|}{ Overweight } \\
\hline Incidence ${ }^{*}$ & $0.81(0.43-1.53)$ & $0.6(0.29-1.05)$ & $1.2(0.63-2.09)$ & $0.8(0.40-1.71)$ & $10.4(2.29-47.39)$ \\
\hline Prevalence ${ }^{\dagger}$ & $1.62(0.94-2.79)$ & $1.3(0.80-2.18)$ & $3.77(2.30-6.18)$ & $3.8(2.35-6.28)$ & $10.8(6.25-18.73)$ \\
\hline \multicolumn{6}{|l|}{ Obesity } \\
\hline \multicolumn{6}{|l|}{ Incidence ${ }^{*}$} \\
\hline Prevalence ${ }^{\dagger}$ & $2.42(1.62-3.62)$ & $1.7(1.14-2.50)$ & $4.3(3.26-5.65)$ & $17.5(11.74-26.18)$ & $125(55.56-285.71)$ \\
\hline \multicolumn{6}{|l|}{ Boys $(n=305)$} \\
\hline Age (mo) (mean) & 0 & 5.1 & 23.1 & 38.9 & 62.5 \\
\hline \multicolumn{6}{|l|}{ Overweight } \\
\hline Incidence ${ }^{*}$ & $0.94(0.46-1.96)$ & $0.7(0.41-1.36)$ & $0.6(0.34-1.17)$ & $1(0.41-2.24)$ & $2.9(1.14-7.38)$ \\
\hline Prevalence & $1.33(1.04-1.70)$ & $2.5(2.04-3.05)$ & $2.5(2.06-3.04)$ & $5.3(4.28-6.44)$ & $21(16.26-26.95)$ \\
\hline \multicolumn{6}{|l|}{ Obesity } \\
\hline \multicolumn{6}{|l|}{ Incidence ${ }^{*}$} \\
\hline Prevalence $^{\dagger}$ & $1.05(0.71-1.57)$ & $5.6(3.63-8.49)$ & $6.2(4.46-8.54)$ & $8.4(6.22-11.21)$ & $53.2(32.68-86.96)$ \\
\hline
\end{tabular}

BMI, body mass index; OR (95\% CI), odds ratio (95\% confidence interval).

* Defined as $1<$ BMI $Z \leq 2$.

$\dagger$ Defined as BMI $Z>2$.

$\ddagger$ The fact that no data of incidence appears in this table (in contrast to the previous one) is due to its low occurrence (5-10\%); associations at such low proportions give very high confidence intervals. 
there were positive associations between early risk factors and degree of obesity in midchildhood. A recent article that summarized meta-analyses and systematic reviews regarding the associations between nutrition in pregnancy, infant feeding practices, and later obesity concluded that in developing countries rapid weight gain early in life is associated with height, BMI, and fat-free mass, but not fat mass [31]. Although those studies were done in developing countries, the children included were from a lower socioeconomic condition than those considered in the present study. Our results are similar to those found by the same authors in developed countries, which show that rapid weight gain during infancy is associated not only with height and BMI, but also with fat mass.

Regarding the presence of overweight (BMI $Z$ score $>1$ ) in the early years, our study shows that in all periods this condition was associated with increased risk of obesity. Similar results were obtained from a recent longitudinal study that evaluated the annual and cumulative IOB among 7738 U.S. children who attended kindergarten in 1998 and were followed over $9 \mathrm{y}$. The authors found that almost $50 \%$ of the children who became obese during that period were overweight already in kindergarten, implying that the increase in IOW probably occurred before $5 \mathrm{y}$ of age [33]. Conversely, the risk of central obesity emerged only when overweight was present after infancy; this suggests that, only at preschool or school age, moderate excess weight would be associated with later metabolic abnormalities as was reported a decade ago [34] with evidence that adiposity after $2 \mathrm{y}$ would be more detrimental for future metabolic risks. These results have practical implications with respect to the clinical management of overweight children, suggesting that more conservative approaches could be taken before $2 \mathrm{y}$ of age. For example, the American Academy of Pediatrics [35] recommends targeting obesity starting at birth, and also recommends that clinicians encourage families to make positive changes in obesity risk behaviors if the child is at increased risk of obesity, such as being overweight with risk factors such as obese parents, or mothers with diabetes or other chronic diseases.

Our study also suggests that all periods after birth in which children present excess weight are relevant in terms of defining future obesity and central obesity risks. It has been proposed that infancy and the period of adiposity rebound (preschool years) would be particularly relevant for defining future obesity risk. However, consistent with our findings, Baird et al. [5] concluded in their review that there was no evidence to suggest that rapid growth during a particular interval between 0 and $2 \mathrm{y}$ was more strongly associated with subsequent obesity. A recent publication [36] confirmed this finding in a sample of Australian children, concluding that there are no critical periods before $9 \mathrm{y}$, and as stated by Gardner et al. [10], weight gained by $5 \mathrm{y}$ of age is closely associated to weight at $9 \mathrm{y}$.

The strengths of this study include that the analyses are based on a medium-sized cohort of children with repeated measurements from birth, and sex-specific incidence and prevalence of overweight and obesity in each period. Also, we differentiated the probability of developing general from central obesity, which is a better predictor of adiposity and thus metabolic syndrome.

There are, however, some limitations to be noted. WC was assessed from $4 \mathrm{y}$ onward; thus, changes in central obesity prevalence between birth and $4 \mathrm{y}$ could not be evaluated. The age of the children within each period was not the same for all, because of the classification of anthropometric measurements into periods by whichever was closest to the upper limit of the specific period. The SD for that measurement varied by period, from a very small one ( 0.4 to $0.6 \mathrm{mo}$ ) in the first period to 4.8 to
$5.2 \mathrm{mo}$ in the last period. Although this difference can conceal differences between subjects, the use of $Z$ scores, which standardize by age and sex in all comparisons, allows us to assume that error is randomly distributed within categories and therefore no systematic bias can be expected.

\section{Conclusions}

Among Chilean children from middle-low-income and lowincome households, most of the new cases of obesity/overweight are found in infants. Moreover, we found that children who are obese in any period postnatal and those who are overweight, after birth, but particularly after infancy, have an increased risk of being obese or centrally obese at $7 \mathrm{y}$, indicating tracking of these conditions. We did not find evidence that there are critical periods in early life for developing obesity/central obesity; however, our data did suggest that efforts should be directed towards the prevention of excessive weight gain from birth.

\section{Acknowledgments}

This work was supported by grants from the Chilean National Council on Science and Technology (FONDECYT Grants 1090252 and 1100206). We thank all the study personnel, particularly Daniela Gonzalez, for field work coordination; we are also indebted to all the participants of the Growth and Obesity Chilean Cohort Study who continue supporting our work.

Conflict of interest: The authors declare that they have no conflict of interest.

Authors' contribution: The study was conceived and designed by J.K., C.C., and M.M. Data were analyzed by M.M. and C.C. M.C. and R.U. read, revised and corrected all the drafts.

\section{References}

[1] Jacoby E, Grajeda R, Contreras A, Hospedales J. The epidemic of childhood obesity in the Americas must be stopped: governmental and PAHO leadership are crucial. Int J Obes Suppl 2013;3:S15-7.

[2] Junta Nacional de Auxilio Escolar y Beca, Santiago. 2014. Available at: http://www.junaeb.cl/. Accessed April, 2015.

[3] The Organisation for Economic Co-operation and Development. Obesity update 2014. Paris: OECD; 2014.

[4] Dietz WH. Critical periods in childhood for the development of obesity. Am J Clin Nutr 1994;59:955-9.

[5] Baird J, Fisher D, Lucas P, Kleijnen J, Roberts H, Law C. Being big or growing fast: systematic review of size and growth in infancy and later obesity. BMJ 2005;331:929.

[6] Dennison BA, Edmunds LS, Stratton HH, Pruzek RM. Rapid infant weight gain predicts childhood overweight. Obesity (Silver Spring) 2006;14:491-9.

[7] Gillman MW. The first months of life: a critical period for development of obesity. Am J Clin Nutr 2008;87:1587-9.

[8] Stettler N, Zemel BS, Kumanyika S, Stallings VA. Infant weight gain and childhood overweight status in a multicenter, cohort study. Pediatrics 2002;109:194-9.

[9] Taveras EM, Rifas-Shiman SL, Belfort MB, Kleinman KP, Oken E, Gillman MW. Weight status in the first 6 months of life and obesity at 3 years of age. Pediatrics 2009;123:1177-83.

[10] Gardner DS, Hosking J, Metcalf BS, Jeffery AN, Voss LD, Wilkin TJ. Contribution of early weight gain to childhood overweight and metabolic health: a longitudinal study (EarlyBird 36). Pediatrics 2009;123:e67-73.

[11] Hughes AR, Sherriff A, Lawlor DA, Ness AR, Reilly JJ. Incidence of obesity during childhood and adolescence in a large contemporary cohort. Prev Med 2011;52:300-4.

[12] Kain J, Corvalan C, Lera L, Galvan M, Uauy R. Accelerated growth in early life and obesity in preschool Chilean children. Obesity (Silver Spring) 2009; $17: 1603-8$.

[13] Kain J, Corvalán C, Lera L, Galván M, Weisstaub G, Uauy R. Asociación entre el índice de masa corporal y la talla desde el nacimiento hasta los 5 años en preescolares chilenos. Rev Med Chil 2011;139:606-12.

[14] Corvalán C, Uauy R, Kain J, Martorell R. Obesity indicators and cardiometabolic status in 4-y-old children. Am J Clin Nutr 2010;91:166-74. 
[15] Gonzalez L, Pereira A, Kain J,Garmendia M, Uauy R. Early adiposity rebound is associated with metabolic risk in 7-year-old children. Int J Obes (Lond) 2014;38:1299-304.

[16] World Health Organization (WHO), 2006. Available at: http://www.who. int/childgrowth/en/. Accessed March, 2015.

[17] World Health Organization (WHO), 2007. Available at: http://www.who. int/childgrowth/en/. Accessed March, 2015.

[18] Blüher S, Molz E, Wiegand S, Otto KP, Sergeyev E, Tuschy S, et al. Body mass index, waist circumference, and waist-to-height ratio as predictors of cardiometabolic risk in childhood obesity depending on pubertal development. J Clin Endocrinol Metab 2013;98:3384-93.

[19] Kitsantas P, Gaffney KF. Risk profiles for overweight/obesity among preschoolers. Early Hum Dev 2010;86:563-8.

[20] Andersen LG, Baker JL, Sorensen TI. Contributions of incidence and persistence to the prevalence of childhood obesity during the emerging epidemic in Denmark. PLoS One 2012;7:e42521-8.

[21] de Beer M, Vrijkotte TG, Fall CH, van Eijsden M, Osmond C, Gemke RJ. Associations of infant feeding and timing of linear growth and relative weight gain during early life with childhood body composition. Int J Obes (Lond) 2015;39:586-92.

[22] Koontz MB, Gunzler DD, Presley L, Catalano PM. Longitudinal changes in infant body composition: association with childhood obesity. Pediatr Obes 2014;9:e141-4.

[23] Kristiansen AL, Bjelland M, Brantsæter AL, Haugen M, Meltzer HM, Nystad W, et al. Tracking of body size from birth to 7 years of age and factors associated with maintenance of a high body size from birth to 7 years of age-the Norwegian Mother and Child Cohort study (MoBa). Public Health Nutr 2015;18:1746-55.

[24] Kato R, Kubota M, Yasui Y, Hayashi Y, Higashiyama Y, Nagai A. Retrospective tracking of young obese children back to birth in Japan: special attention to the relationship with parental obesity. Asia Pac J Clin Nutr 2014;23:641-50.

[25] Johannsson E, Arngrimsson SA, Thorsdottir I, Sveinsson T. Tracking of overweight from early childhood to adolescence in cohorts born 1988 and 1994: overweight in a high birth weight population. Int J Obes (Lond) 2006;30:1265-71.
[26] Rios-Castillo I, Cerezo S, Corvalán C, Martínez M, Kain J. Risk factors during the prenatal period and the first year of life associated with overweight in 7-year-old low-income Chilean children. Matern Child Nutr 2015;11:595-605.

[27] Kain J, Orellana Y, Leyton B, Taibo M, Vio F. Association between socioeconomic vulnerability and height with obesity in low-income Chilean children in the transition from preschool to first grade. Ecol Food Nutr 2014;3:241-55.

[28] Pryor LE, Tremblay RE, Boivin M, Touchette E, Dubois L, Genolini C, et al. Developmental trajectories of body mass index in early childhood and their risk factors: an 8-year longitudinal study. Arch Pediatr Adolesc Med 2011;165:906-12.

[29] Druet C, Stettler N, Sharp S, Simmons RK, Cooper C, Smith GD, et al. Prediction of childhood obesity by infancy weight gain: an individual-level meta-analysis. Paediatr Perinat Epidemiol 2012;26:19-26.

[30] Reilly JJ, Armstrong J, Dorosty AR, Emmett PM, Ness A, Rogers I, et al. Early life risk factors for obesity in childhood: cohort study. BMJ 2005;330:1357.

[31] Yang Z, Huffman SL. Nutrition in pregnancy and early childhood and associations with obesity in developing countries. Matern Child Nutr 2013;9:105-19.

[32] Robinson S, Cozier S, Harvey N, Barton B, Law C, Godfrey K, et al. Modifiable early-life risk factors for childhood adiposity and overweight: an analysis of their combined impact and potential for prevention. Am J Clin Nutr 2015;101:368-75.

[33] Cunningham S, Kramer M, Narayan V. Incidence of childhood obesity in United States. N Engl J Med 2014;370:403-11.

[34] Bhargava SK, Sachdev HS, Fall CH, Osmond C, Lakshmy R, Barker DJ, et al. Relation of serial changes in childhood body-mass index to impaired glucose tolerance in young adulthood. N Engl J Med 2004;350:865-75.

[35] Barlow SE, Committee E. Expert committee recommendations regarding the prevention, assessment, and treatment of child and adolescent overweight and obesity: summary report. Pediatrics 2007;120:S164-92.

[36] Giles LC, Whitrow MJ, Rumbold AR, Davies CE, de Stavola B, Pitcher JB, et al. Growth in early life and the development of obesity by age 9 years: are there critical periods and a role for an early life stressor? Int J Obes (Lond) 2013;37:513-9. 